\title{
28 Research Square \\ Evaluation of Thiol Disulfide Balance in Adolescents With Vitamin B12 Deficiency
}

Mehmet Semih Demirtas ( $\nabla$ md.semihdemirtas@gmail.com )

Aksaray University Training and Research Hospital, Department of Pediatrics https://orcid.org/00000003-2965-1811

Huseyin Erdal

Aksaray University, Faculty of Medicine, Department of Pediatrics

\section{Research Article}

Keywords: Vitamin B12, Child, Adolescent, Oxidative stress, Thiol, Homocysteine, Thiol/disulfide balance

Posted Date: February 15th, 2022

DOI: https://doi.org/10.21203/rs.3.rs-1318028/v1

License: (1) This work is licensed under a Creative Commons Attribution 4.0 International License.

Read Full License 


\section{Abstract}

\section{Background}

Vitamin B12 is an important vitamin for metabolism and affects many mechanisms in the body, such as neuronal migration, DNA synthesis, neurotransmitter synthesis, brain and cognitive development. Increasing oxidative stress in the body leads damage to the growth and development process of childhood, but also plays a crucial role in the pathogenesis of many diseases encountered in the pediatric period. Our aim is to investigate whether B12 deficiency is associated with dynamic thiol/disulfide homeostasis in adolescent patients.

\section{Methods}

The study was conducted with 90 patients, including 45 patients in the case and control groups. Patients between the ages of 11-18 were selected who applied to the outpatient clinic for the first time with one of the complaints of headache, decreased school performance, dizziness, and fatigue. Hemogram, vitamin B12, homocysteine levels and oxidative stress parameters such as native and total thiol, disulfide levels and ratios of disulfide/native thiol, disulfide/total thiol, native thiol/total thiol were measured from the patients.

\section{Results}

Vitamin B12 level was found to be significantly lower in vitamin B12 deficiency. group $(p<0.001)$. The serum disulfide level was found to be $27.5 \pm 8.38$ in the case group and $20.5 \pm 8.36$ in the control group $(p<0.001)$. In the multiple linear regression analysis, it was determined that the independent variables of native thiol, homocysteine and disulfide had effects on vitamin B12 levels $(p<0.001, p<0.001, p<0.005$ respectively; $\mathrm{R}^{2}=0.62$ ).

\section{Conclusion}

These findings are remarkable in that vitamin B12 deficiency has an effect on oxidative stress in adolescents. The increase in oxidative stress parameters in the patient group may suggest that oxidative stress plays a vital role in vitamin B12 deficiency in adolescence.

\section{Background}

Vitamin B12 is an essential vitamin that is vital for DNA synthesis, neuronal migration, neurotransmitter synthesis, brain and cognitive development. In case of insufficient vitamin B12 status, it can have lasting effects on neuronal, hematological and cognitive levels which may be irreversible due to the impair in these development processes [1]. Vitamin B12 deficiency is seen with findings such as irritability, apathy, and developmental regression in infancy due to disruption and damage in neuronal myelination and synaptogenesis in the central nervous system. Moreover in the adolescent age group, it is a condition that causes cognitive and mood disorders such as decreased school success, headache, and dizziness. [2, 3]. 
In the absence of typical macrocytic anemia findings, it is difficult to diagnose vitamin B12 deficiency in children and adolescents. However, children with vitamin B12 deficiency with normal hematological indicators may have symptoms of different systems, with central nervous system findings being more prominent [4].

Vitamin B12 plays an important role in the maintenance of glutathione levels, which is an important element of antioxidant capacity, and also, enzymatically processed vitamin B12 contributes to the provision of oxidative balance by acting directly as a superoxide scavenger. Increasing oxidative stress in the body leads damage to the growth and development process of childhood, but also plays an essential role in the pathogenesis of various diseases encountered in the pediatric period [5, 6]. In case of long-term deficiency of vitamin B12, it causes myelination or demyelination of the spinal cord and brain. Exceeding the antioxidant capacity of pro-oxidant components such as delayed myelination, changes in S-adenosyl methionine (SAM)/ S-adenosylhomocysteine (SAH) (SAM/SAH) ratio, neurotrophic imbalance, neurotoxic cytokines, Reactive Oxygen Species (ROS) [7] or demyelination of nerves has been implicated in the pathophysiology of the disease [8].

Thiols containing sulfhydryl groups [9] are involved in the prevention of oxidative stress that develops with the deterioration of oxidative balance in cells. When the body encounters oxidation, thiol groups form disulfide structures and can be reduced back to thiol with the reduction of oxidative stress over time. With this mechanism structure, the body creates a dynamic thiol disulfide balance. Ensuring this balance has a significant role in detoxification systems, signal transmission, mechanism of antioxidant protection and regulation of hormone and enzymatic activities [10]. New studies are carried out in childhood diseases regarding the thiol-disulfide balance, which is one of the new markers of the oxidative system and can provide important information to physicians in the early diagnosis of childhood diseases and neurodevelopmental regression conditions [11].

To the best of our knowledge, no studies have been conducted with a control group to date regarding thiol and thiol/disulfide balance, which are used as a new oxidative stress marker in adolescents with vitamin B12 deficiency. We aimed to investigate dynamic thiol/disulfide homeostasis in adolescent patients with B12 deficiency in this study.

\section{Methods}

\section{Study design}

Our study was planned as a case-control study in a single center with a Training and Research Hospital Pediatrics Clinic in order to examine the relationship between vitamin B12 deficiency and thiol/disulfide hemostasis in adolescence.

\section{Study Population}


The study was planned by selecting 45 of 141 adolescent patients who applied to Aksaray Training and Research Hospital Pediatrics Outpatient Clinic and the control group, was formed by selecting 45 healthy adolescents who did not have any symptoms and applied to the polyclinic to obtain a sports license.

Patients between the ages of 11-18 were selected among the patients who applied to the outpatient clinic for the first time with one of the complaints of headache, decreased school performance, dizziness, and fatigue. Except for vitamin B12 deficiency, patients without iron deficiency anemia and vitamin D deficiency, without any comorbite disease, and with normal cranial magnetic resonance imaging [12] were selected.

Of the 96 patients who were not included in the study because, 43 patients had upper respiratory tract infections such as sinusitis and flu, 33 patients had vitamin D deficiency and iron anemia, 14 patients had comorbidit disease and 2 patients use of antidepressant medication. Four patients were excluded as they were diagnosed with migraine.

\section{Data Collection}

Hemogram, vitamin B12, native and total thiol, disulfide and homocysteine levels were measured from the patients. Serum samples were collected into vacutainer tubes containing EDTA, during routine blood sample taking for the measurement of vitamin B12 and other biochemical parameters, and were centrifuged at $1500 \mathrm{~g} \times 10 \mathrm{~min}$ after sampling. Then, serum samples were portioned and stored $-80^{\circ} \mathrm{C}$ in the eppendorf tube until the time of assay.

\section{Measurement of Thiol/ Disulfide Homeostasis}

In this study, native and total thiol levels were measured with a new spectrophotometric method developed by Erel and Neselioglu [10]. Disulfide levels were calculated the half of the difference between the total and native thiols.

\section{Measurement of Homocysteine Levels}

Homocysteine levels $(6-14 \mu \mathrm{mol} / \mathrm{L})$ were studied with the colorimetric method (automatic analyzer MINDRAY-BS $400^{\circledR}$ device). First, oxidized homocysteine (HCY) is reduced to free HCY. Free HCY then reacts with a co-substrate, catalysed by cycling enzymes, and was significantly amplified. Then through dehydrogenation, $\mathrm{NADH}$ converts to $\mathrm{NAD}+$. The concentration of $\mathrm{HCY}$ in the sample is indirectly proportional to the amount of NADH converted to NAD+.

\section{Statistical analysis}

In this study, the data were analyzed by using the SPSS 22.0 (IBM, USA) statistical package program. Shapiro-Wilk test was used to determine the distribution patterns of the variables. Numerical values were expressed as mean \pm standard deviation, and categorical values were expressed as $n(\%)$. The mean differences between two independent groups were compared using the Student's t-test; The Mann- 
Whitney $U$ test was used to compare the median values that did not fit the parametric distribution. The Kruskal-Wallis test was used to evaluate oxidative stress in the age category divided into three groups. One-way ANOVA was used when differences between the groups were evaluated because the variables showed normal distribution. Linear regression analysis was applied to evaluate the relationship between dependent and independent variables. $\mathrm{P}<0.05$ were considered statistically significant.

\section{Ethics}

Written informed consent was obtained from all parents after the procedures regarding the study were fully explained to the families. This study was approved by ethical committee of Hatay Mustafa Kemal University (protocol number: 2022/10).

\section{Results}

The study consisted of 90 patients, 45 of whom were in the control group and 45 of them were in the control group. While the mean age was $14.1 \pm 1.71$ years in the vitamin B12 deficiency group, it was 14.1 \pm 1.62 years in the control group and there was no difference in age between the two groups $(p=0.21)$. In the vitamin B12 deficiency group, 21 (46.7\%) of the patients were male and 24 (53.3\%) were female; in the control group, $22(48.9 \%)$ of the participants were male and 23 (51.5\%) were female, and there was no significant difference in sex $(p=0.83)$ distribution as in the age factor. There was no significant difference in hemogram parameters such as Hemoglobin ( $\mathrm{Hb}$ ), Red Cell Distribution Width (RDW), Mean corpuscular volume (MCV) between the two groups (Table 1).

Table 1

Demographic features of all participants

\begin{tabular}{|lllll|}
\hline Parameter & Case $(\mathbf{n}=45)$ & Control $(\mathbf{n}=45)$ & p \\
& & $\mathbf{n} \%$ & $\mathbf{n} \%$ & \\
\hline \multirow{2}{*}{ Sex } & Male & $21(46.7 \%)$ & $22(48.9 \%)$ & $0.83^{\text {a }}$ \\
\cline { 2 - 5 } & Female & $24(53.3 \%)$ & $23(51.5 \%)$ & \\
\hline Age & $14.1 \pm 1.71$ & $14.1 \pm 1.62$ & $0.21^{*}$ \\
\hline \multirow{2}{*}{ a. Chi-Square testi, ${ }^{*}$ : Student t test } & \\
\hline
\end{tabular}

When the laboratory parameters of the study groups were compared, the serum vitamin B12 level was found to be significantly lower in the vitamin B12 deficiency group $(p<0.001)$. The serum disulfide level was found to be $27.5 \pm 8.38$ in the case group and $20.5 \pm 8.36$ in the control group $(p<0.001)$. We found that Homocysteine and native thiol levels were significantly increased in the B12 deficient group $(p<0.001$, $p<0.001$, respectively). Total thiol and ratios of disulfide/native, disulfide/total and native /total thiol levels were found to be statistically significant between the case and control groups (Table 2). 
Table 2

The distribution of serum vitamin B12, Homocysteine, hemoglobin parametres and Thiol levels of all subjects.

\begin{tabular}{|llll|}
\hline Parameter & Case $(\mathbf{n = 4 5})$ (Min-Max) & Control $(\mathbf{n = 4 5})$ (Min-Max) & $\mathbf{p}$ \\
\hline Vitamin B12 $(\mathrm{pg} / \mathrm{ml})$ & $161(79-280)$ & $314(107-451)$ & $<0.001$ \\
\hline Homocysteine $(\mu \mathrm{mol} / \mathrm{L})$ & $39.3(22.9-94.9)$ & $17.2(11.6-37.4)$ & $<0.001$ \\
\hline Total Thiol $(\mu \mathrm{mol} / \mathrm{L})$ & $457.6(275-685)$ & $594(243-718)$ & $<0.001$ \\
\hline Native Thiol $(\mu \mathrm{mol} / \mathrm{L})$ & $402.6(243-608)$ & $553(216-688)$ & $<0.001$ \\
\hline Disulfide & $27.5(14-55)$ & $20.5(12-59)$ & $<0.001$ \\
\hline Disulfide/Native Thiol & $7.1(3.6-16.2)$ & $3.9(1.8-12.6)$ & $<0.001$ \\
\hline Disulfide/Total Thiol & $6.1(3.4-12.2)$ & $3.6(1.7-10.1)$ & $<0.001$ \\
\hline Native Thiol/Total Thiol & $87.7(75.6-93.2)$ & $92.9(79.9-96.6)$ & $<0.001$ \\
\hline Hemoglobin & $14.1(11-16.3)$ & $14.2(12.1-16.5)$ & 0.46 \\
\hline MCV & $84(78-95)$ & $83.5(77-86.3)$ & 0.13 \\
\hline RDW & $13.3(11.4-15.9)$ & $12.9(11.8-15.6)$ & 0.62 \\
\hline
\end{tabular}

B12 levels in the case group was $164.4 \pm 41.3$ in the male group and $158 \pm 3.2$ in the female group. When those with B12 levels were examined in terms of gender in case groups, disulfide was found to be $25.2 \pm$ 7.7 in the male group and $29.5 \pm 8.5$ in the female group $(p=0.084)$. No difference was found in other oxidative stress parameters in terms of gender factor (Table 3 ). In order to evaluate the group with B12 deficiency in terms of age, the adolescents in the case group were divided into 3 groups aged 11-13, 1415 and 16-17. There was no significant difference between the values of the patients in terms of age (Table 3). 
Table 3

Distribution of vitamin B12, Homocysteine and Thiol parameters in the case group according to gender and age.

\begin{tabular}{|c|c|c|c|c|c|c|c|}
\hline Parameter & $\begin{array}{l}\text { Male } \\
(n=21)\end{array}$ & $\begin{array}{l}\text { Female } \\
(n=24)\end{array}$ & $P_{1}^{\beta}$ & $\begin{array}{l}\text { Age1* } \\
(n=19)\end{array}$ & $\begin{array}{l}\text { Age2**} \\
(n=12)\end{array}$ & $\begin{array}{l}\text { Age } 3 * * * \\
(n=14)\end{array}$ & $P_{2} \S$ \\
\hline $\begin{array}{l}\text { Vitamin B12 } \\
(\mathrm{pg} / \mathrm{ml})\end{array}$ & $\begin{array}{l}164.4(94- \\
211)\end{array}$ & $\begin{array}{l}178(79- \\
280)\end{array}$ & 0.37 & $\begin{array}{l}161.6(94- \\
256)\end{array}$ & $\begin{array}{l}168(106- \\
224)\end{array}$ & $\begin{array}{l}155(79- \\
280)\end{array}$ & 0.60 \\
\hline $\begin{array}{l}\text { Homocysteine } \\
(\mu \mathrm{mol} / \mathrm{L})\end{array}$ & $\begin{array}{l}35.8 \\
(22.9- \\
94.9)\end{array}$ & $\begin{array}{l}42.4(23.5- \\
86.5)\end{array}$ & 0.09 & $\begin{array}{l}38.6 \\
(22.9- \\
94.9)\end{array}$ & $\begin{array}{l}34(23.4- \\
57.1)\end{array}$ & $\begin{array}{l}44.8 \\
(26.3- \\
86.5)\end{array}$ & 0.14 \\
\hline $\begin{array}{l}\text { Total Thiol } \\
(\mu \mathrm{mol} / \mathrm{L})\end{array}$ & $\begin{array}{l}234.2 \\
(275-594)\end{array}$ & $\begin{array}{l}478(325- \\
685)\end{array}$ & 0.15 & $\begin{array}{l}461.8 \\
(298-685)\end{array}$ & $\begin{array}{l}462.4 \\
(275-630)\end{array}$ & $\begin{array}{l}447.8 \\
(305-658)\end{array}$ & $0.8 \varepsilon$ \\
\hline $\begin{array}{l}\text { Native Thiol } \\
(\mu \mathrm{mol} / \mathrm{L})\end{array}$ & $\begin{array}{l}383.8 \\
(243-510)\end{array}$ & $\begin{array}{l}419.1 \\
(266-608)\end{array}$ & 0.19 & $\begin{array}{l}405(243- \\
594)\end{array}$ & $\begin{array}{l}406(245- \\
578)\end{array}$ & $\begin{array}{l}396.2 \\
(266-608)\end{array}$ & $0.8 \mathrm{c}$ \\
\hline Disulfide & $\begin{array}{l}25.2(14- \\
44)\end{array}$ & $\begin{array}{l}29.5(15- \\
55)\end{array}$ & 0.08 & $\begin{array}{l}28.3(20- \\
45.5)\end{array}$ & $\begin{array}{l}28.2(14- \\
55)\end{array}$ & $\begin{array}{l}25.7(15- \\
43)\end{array}$ & 0.52 \\
\hline $\begin{array}{l}\text { Disulfide/Native } \\
\text { Thiol }\end{array}$ & $\begin{array}{l}6.8(3.6- \\
14.6)\end{array}$ & $\begin{array}{l}7.4(4.1- \\
16.2)\end{array}$ & 0.39 & $\begin{array}{l}7.4(4.1- \\
14.6)\end{array}$ & $\begin{array}{l}6.9(36- \\
11.5)\end{array}$ & $\begin{array}{l}6.9(4.1- \\
16.2)\end{array}$ & $0.6 \mathrm{c}$ \\
\hline $\begin{array}{l}\text { Disulfide/Total } \\
\text { Thiol }\end{array}$ & $\begin{array}{l}5.9(3.4- \\
11.3)\end{array}$ & $\begin{array}{l}6.3(3.8- \\
12.2)\end{array}$ & 0.39 & $\begin{array}{l}6.4(3.8- \\
11.3)\end{array}$ & $\begin{array}{l}6.1(3.4- \\
9.3)\end{array}$ & $\begin{array}{l}5.9(3.8- \\
12.2)\end{array}$ & 0.68 \\
\hline $\begin{array}{l}\text { Native } \\
\text { Thiol/Total } \\
\text { Thiol }\end{array}$ & $\begin{array}{l}88.1 \\
(77.4- \\
93.2)\end{array}$ & $\begin{array}{l}87.3(75.6- \\
92.4)\end{array}$ & 0.37 & $\begin{array}{l}87.2 \\
(77.4- \\
92.4)\end{array}$ & $\begin{array}{l}87.8 \\
(81.4- \\
93.2)\end{array}$ & $\begin{array}{l}88.2 \\
(75.6- \\
92.4)\end{array}$ & 0.68 \\
\hline \multicolumn{8}{|c|}{$\beta=$ Mann-Whitney U test, $\$=$ Kruskal Wallis test } \\
\hline
\end{tabular}

In multivariate statistical analyzes, gender, age, total thiol, native thiol, disulfide, hemoglobin, MCV, RDW, and homocysteine associated with or thought to be associated with vitamin B12 deficiency were included in the linear regression model as candidate risk factors. In the multiple linear regression analysis, it was determined that the independent variables of native thiol, homocysteine and disulfide had effects on vitamin $B 12$ levels $\left(p<0.001, p<0.001, p<0.005\right.$ respectively; $\left.R^{2}=0.62\right)$.

\section{Discussion}

To our knowledge, this is the first study to investigate serum oxidative metabolism vitamin B12 deficiency in adolescents. We found that the native thiol levels were lower in the group with vitamin B12 deficiency, while the disulfide level was significantly higher ( $<<0.001, p<0.001$, respectively). We determined higher $\mathrm{HCY}$ level in patient group that had vitamin B12 deficiency $(p<0.001)$. We also found that native thiol, 
homocysteine and disulfide parameters have an effect on vitamin B12 deficiency $(p<0.001, p<0.001$, $p<0.005$ respectively; $R 2=0.62$ ).

Vitamin B12 deficiency remains the most common cause of childhood megaloblastic anemia [13]. It is an important vitamin that is vital for metabolism and affects many mechanisms in the body, such as supporting DNA synthesis necessary for cell division and reproduction, synthesis of myelin sheaths, being a cofactor of methionine synthase and L-methyl-malonyl-coenzyme A mutase enzymes at the cellular level. Early diagnosis and initiation of treatment for vit-B12 deficiency in infants and adolescents is important in preventing severe anemia, permanent neurological deficits and loss of cognitive function. School-age children anda adolescents with vitamin B12 deficiency show retardation compared to their peers in long-term memory function and cognitive skills such as difficulty concentrating $[7,14,15]$. Cobalamin deficiency reduces the activity of methionine synthase, which is involved in cellular methylation reactions, gene expression and protein synthesis, and increases the oxidative stress load of metabolism $[9,16,17]$. Güney et al. in his study of vitamin B12 deficiency in adult patients, he showed that oxidative stress did not increase in the vitamin B12 deficient group [18]. In another study on oxidative stress in children aged 4-9 years with cobalamin and iron deficiency anemia, it was shown that thiobarbituric acid derivatives (TBARS), an important marker of oxidative stress, increased levels [19]. One of the most important results of our study is that we found that native thiol levels, a new marker of oxidative stress, were decreased in adolescent patients with neurological findings $(p<0.001)$.

The effects of vitamin B12 deficiency on the central and peripheral nervous systems are explained by the accumulation of methylmalonic acid and homocysteine in the tissue and plasma as a result of the defect in enzymatic reactions. The activity of the methylmalonyl-coenzyme A mutase enzyme, which is the cofactor of vitamin B12 and takes part in the conversion of Methylmalonyl-CoA to succinylCoA, causes the accumulation of methylmalonyl-Coa in the body. In addition, the interruption of methionine synthase activity causes an increase in serum homocysteine levels. This increase in homocysteine, which has prooxidant properties, increases oxidative stress $[17,19,20]$. A study of human epidermal melanocytes treated with a B12 antagonist showed an increase in ROS production of over $100 \%$ [21]. This situation causes an increase in reactive oxygen species [7], especially by interrupting methionine synthase activity and increasing Hydrogen peroxide $\left(\mathrm{H}_{2} \mathrm{O}_{2}\right)$ production by auto-oxidation of increased homocysteine levels [22]. In line with the literature, we found homocysteine and disulfide affected B12 level is a significant result indicating increased oxidative stress level $\left(p<0.001, p<0.005\right.$, respectively; $\left.R^{2}=0.62\right)$.

\section{Strengths And Limitations}

Although our most obvious limitation in this study was the relatively small sample size, the exclusion of concomitant disease and other anemia conditions in our vitamin B12 deficiency sample increased the reliability of our study.

We think that it will be a precursor to studies on the relationship between vitamin B12 deficiency and oxidative stress in childhood and prospective cohort studies. 


\section{Conclusions}

Diagnosis and treatment of vitamin B12 deficiency is important in cases of regression in cognitive functions and finding neurological symptoms whom seen in adolescence. We think that native thiol and disulfite levels can be used as a marker to determine oxidative stress due to vitamin B12 deficiency in the early period in adolescents.

\section{Abbreviations}

SAM: S-adenosyl methionine

SAH: S-adenosylhomocysteine

H2O2: Hydrogen peroxide

MMA: Serum methylmalonic acid

TBARS: Thiobarbituric acid derivatives

ROS: Reactive Oxygen Species

HCY: Homocysteine

$\mathrm{Hb}$ : Hemoglobine

\section{Declarations}

\section{Ethics approval and consent to participate}

This study protocol was approved by the ethical committee of Hatay Mustafa Kemal University (protocol number: 2022/10). Informed consents were obtained the particpants parents.

\section{Consent for publication}

Not applicable. There is no personel information provided in this paper.

\section{Availability of data and materials}

The data gathered in this study can be requested from the corresponding author reasonably.

\section{Competing interests}

The authors reported no competing interests.

\section{Funding}


The authors did not receive support from any organization for the submitted work.

\section{Authors' contributions}

Conception and design of the research: MSD, Acquisition of data: HE and MSD. Analysis and interpretation of data: HE. Statistical analysis: MSD. Drafting the manuscript: MSD. Revision of manuscript for important intellectual content: HE and MSD.

All authors read and approved the final manuscript.

\section{Acknowledgments}

The authors thank the patients anda their parents to participating in the study on a voluntary basis.

\section{CONFLICTS OF INTEREST AND SOURCES OF FUNDING}

The authors disclose that they received no financial support for this work. The authors declare no conflict of interest.

\section{References}

1. Oh R, Brown DL. Vitamin B12 deficiency. Am Fam Physician. 2003;67(5):979-86.

2. Black MM. Effects of vitamin B12 and folate deficiency on brain development in children. Food Nutr Bull. 2008;29(2 Suppl):S126-31. https://dx.doi.org/10.1177/15648265080292S117.

3. Incecik F, Herguner MO, Altunbasak S, Leblebisatan G. Neurologic findings of nutritional vitamin B12 deficiency in children. Turk J Pediatr. 2010;52(1):17-21.

4. Georgieff MK, Ramel SE, Cusick SE. Nutritional influences on brain development. Acta Paediatr. 2018;107(8):1310-21. https://dx.doi.org/10.1111/apa.14287.

5. Chan W, Almasieh M, Catrinescu MM, Levin LA. Cobalamin-Associated Superoxide Scavenging in Neuronal Cells Is a Potential Mechanism for Vitamin B12-Deprivation Optic Neuropathy. Am J Pathol. 2018;188(1):160-72. https://dx.doi.org/10.1016/j.ajpath.2017.08.032.

6. Karamshetty V, Acharya JD, Ghaskadbi S, Goel P. Mathematical Modeling of Glutathione Status in Type 2 Diabetics with Vitamin B12 Deficiency. Front Cell Dev Biol. 2016;4:16. https://dx.doi.org/10.3389/fcell.2016.00016.

7. Quadros EV. Advances in the understanding of cobalamin assimilation and metabolism. $\mathrm{Br} \mathrm{J}$ Haematol. 2010;148(2):195-204. https://dx.doi.org/10.1111/j.1365-2141.2009.07937.x.

8. Dror DK, Allen LH. Effect of vitamin B12 deficiency on neurodevelopment in infants: current knowledge and possible mechanisms. Nutr Rev. 2008;66(5):250-5. https://dx.doi.org/10.1111/j.1753-4887.2008.00031.x.

9. Al-Maskari MY, Waly MI, Ali A, Al-Shuaibi YS, Ouhtit A. Folate and vitamin B12 deficiency and hyperhomocysteinemia promote oxidative stress in adult type 2 diabetes. Nutrition. 2012;28(7- 
8):e23-6. https://dx.doi.org/10.1016/j.nut.2012.01.005.

10. Erel O, Neselioglu S. A novel and automated assay for thiol/disulphide homeostasis. Clin Biochem. 2014;47(18):326-32. https://dx.doi.org/10.1016/j.clinbiochem.2014.09.026.

11. Erenler AK, Yardan T. Clinical Utility of Thiol/Disulfide Homeostasis. Clin Lab. 2017;63(5):867-70. https://dx.doi.org/10.7754/Clin.Lab.2017.161117.

12. Kasap B, Duman N, Ozer E, Tatli M, Kumral A, Ozkan H. Transient tachypnea of the newborn: predictive factor for prolonged tachypnea. Pediatr Int. 2008;50(1):81-4. https://dx.doi.org/10.1111/j.1442-200X.2007.02535.x.

13. Bahadir A, Reis PG, Erduran E. Oral vitamin B12 treatment is effective for children with nutritional vitamin B12 deficiency. J Paediatr Child Health. 2014;50(9):721-5. https://dx.doi.org/10.1111/jpc.12652.

14. Scalabrino G, Veber D, Mutti E. New pathogenesis of the cobalamin-deficient neuropathy. Med Secoli. 2007;19(1):9-18.

15. Scalabrino G, Peracchi M. New insights into the pathophysiology of cobalamin deficiency. Trends Mol Med. 2006;12(6):247-54. https://dx.doi.org/10.1016/j.molmed.2006.04.008.

16. Huemer M, Baumgartner MR. The clinical presentation of cobalamin-related disorders: From acquired deficiencies to inborn errors of absorption and intracellular pathways. J Inherit Metab Dis. 2019;42(4):686-705. https://dx.doi.org/10.1002/jimd.12012.

17. Rogers EJ, Chen S, Chan A. Folate deficiency and plasma homocysteine during increased oxidative stress. N Engl J Med. 2007;357(4):421-2. https://dx.doi.org/10.1056/NEJMc066569.

18. Guney T, Alisik M, Akinci S, Neselioglu S, Dilek I, Erel O. Evaluation of oxidant and antioxidant status in patients with vitamin B12 deficiency. Turk J Med Sci. 2015;45(6):1280-4. https://dx.doi.org/10.3906/sag-1407-81.

19. Askar TK, Buyukleblebici O, Hismiogullari AA, Hunkerler Z. Oxidative stress, hepcidin and nesfatin-I status in childhood iron and vitamin B12 deficiency anemias. Adv Clin Exp Med. 2017;26(4):621-5. https://dx.doi.org/10.17219/acem/62829.

20. Sibrian-Vazquez M, Escobedo JO, Lim S, Samoei GK, Strongin RM. Homocystamides promote freeradical and oxidative damage to proteins. Proc Natl Acad Sci U S A. 2010;107(2):551-4. https://dx.doi.org/10.1073/pnas.0909737107.

21. Rzepka Z, Respondek M, Rok J, Beberok A, K OP, Gryko D et al. Vitamin B12 Deficiency Induces Imbalance in Melanocytes Homeostasis-A Cellular Basis of Hypocobalaminemia Pigmentary Manifestations. Int J Mol Sci. 2018;19(9). https://dx.doi.org/10.3390/ijms19092845.

22. Tyagi N, Sedoris KC, Steed M, Ovechkin AV, Moshal KS, Tyagi SC. Mechanisms of homocysteineinduced oxidative stress. Am J Physiol Heart Circ Physiol. 2005;289(6):H2649-56. https://dx.doi.org/10.1152/ajpheart.00548.2005. 